\title{
LOCALIZATION OF NEURONS AFFERENT TO THE TELENCEPHALON IN A PRIMITIVE BONY FISH, POLYPTERUS PALMAS
}

\author{
R. GLENN NORTHCUTT \\ Division of Biological Sciences, University of Michigan, Ann Arbor, MI 48109 (U.S.A.) \\ (Received December 22nd, 1980; Accepted January 8th, 1981)
}

Telencephalic horseradish peroxidase injections in bichirs reveal projections from the dorsal thalamus, posterior tuberculum, nucleus of the torus lateralis, superior raphe and locus coeruleus. Comparison of these data with those from tetrapods reveals a number of diencephalic homologies.

It has recently become obvious that olfactory input to the telencephalon in rayfinned fishes is quite restricted $[1,3,6,8,12,18]$, and that ascending non-olfactory projections reach telencephalic levels $[4,7,9,10,14,19]$. Although most studies have focused on teleosts - advanced ray-finned fishes - Braford and Northcutt [4] reported diencephalic projections to the telencephalon in bichirs, the most primitive living ray-finned fishes. That study involved large diencephalic lesions and did not establish the number or exact location of afferents to the telencephalon. To resolve these questions, various telencephalic regions in bichirs were injected with horseradish peroxidase (HRP), and more caudal brain regions were examined for retrograde transport of HRP.

Fourteen bichirs, Polypterus palmas, were anesthetized by immersion in $0.1 \%$ methanesulfonate solution and the telencephalic hemispheres exposed. A 00 insect pin, coated with HRP paste, was inserted into a specific telencephalic site, and the surface of the brain was flushed with saline solution to remove excess HRP. The fish were allowed to survive $4-8$ days postoperatively at $28^{\circ} \mathrm{C}$ before being reanesthetized and perfused with cold $0.1 \mathrm{M}$ phosphate buffer followed by $2 \%$ glutaraldehyde in $0.1 \mathrm{M}$ phosphate buffer. The brains were removed, washed in $10 \%$ sucrose phosphate buffer, and embedded in gelatin blocks. The gelatin blocks were fixed for an additional $4 \mathrm{~h}$ in $2 \%$ glutaraldehyde, sectioned at $35 \mu \mathrm{m}$, and processed by the tetramethylbenzidine protocol [11] to visualize the HRP. Brain sections were then mounted and counterstained with $1 \%$ neutral red to identify cell groups. The nomenclature used is that of Northcutt and Braford [12] for the telencephalon and Braford and Northcutt [5] for the diencephalon.

All survival times yielded positive results; both anterograde and retrograde labeling were observed in the forebrain bundles and retrogradely filled cells in more 
caudal areas. Case 11, charted in Fig. 1, sustained the largest single injection and exhibits all cell groups revealed by more restricted injections.

Four separate dorsal thalamic nuclei revealed retrogradely labeled cells following telencephalic injections. Labeled cells were observed bilaterally in the anterior thalamic nucleus and in a migrated cell group (nucleus a) immediately lateral to the anterior thalamic nucleus (Fig. 1E, F), as well as in the ipsilateral dorsal posterior and central posterior thalamic nuclei (Fig. 1G). No ventral thalamic, hypothalamic
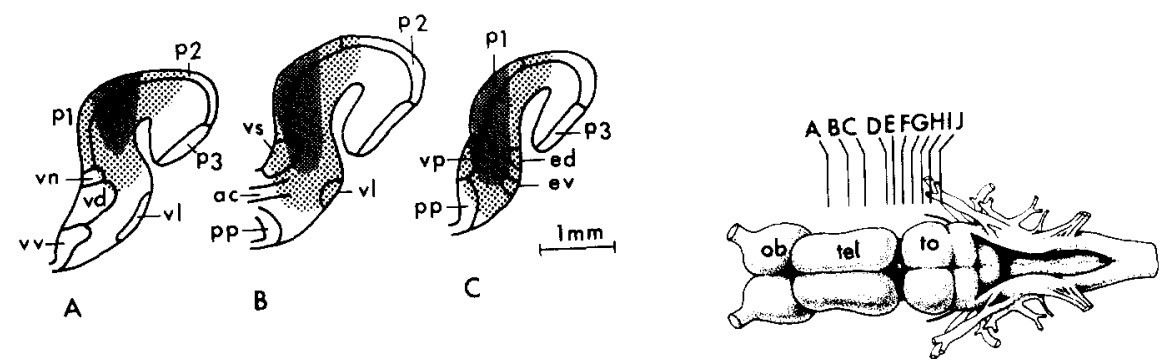

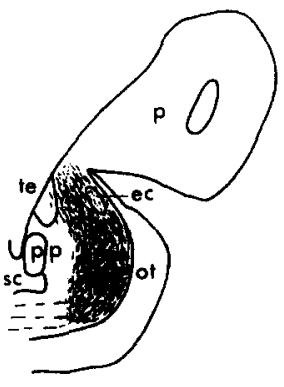

D

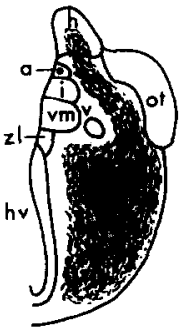

$E$

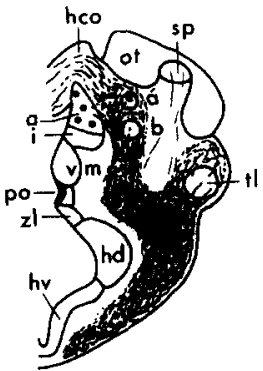

F

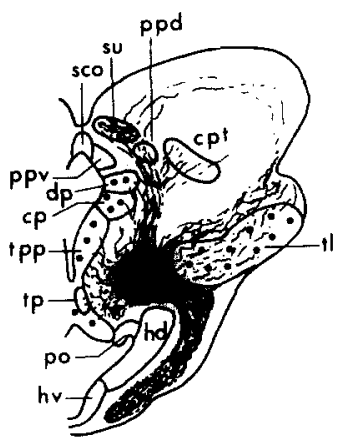

G
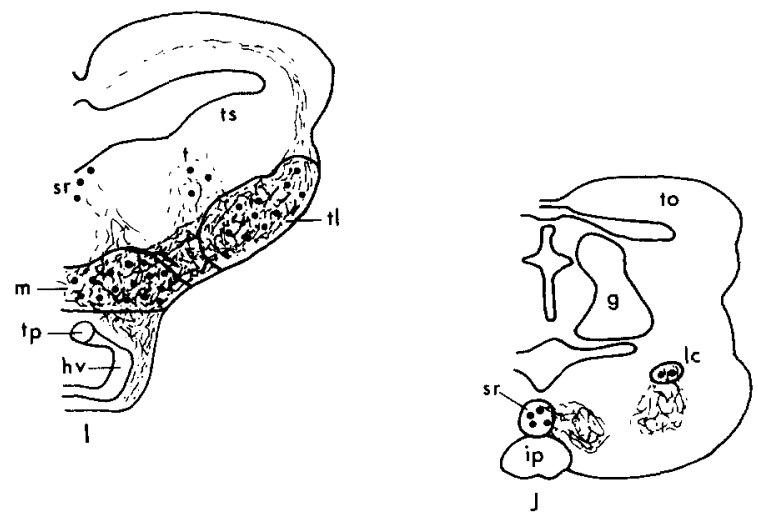
or pretectal nuclei revealed retrogradely labeled cells, suggesting that these areas do not project to the telencephalon; however, an extensive region of the diencephalon, caudal to the ventral thalamus, exhibited numerous retrogradely labeled cells (Fig. 1G-I).

Labeled cells were seen ipsilaterally in the periventricular nucleus (tpp, Fig. 1G, $\mathrm{H}$ ) and bilaterally in nucleus medianus (m, Fig. 1H, I) of the posterior tuberculum. Labeled cells were also seen bilaterally in a more lateral complex termed the nucleus of the torus lateralis (tl, Fig. 1G-I). Bichirs do not possess a distinct glomerular complex, and their lateral toral nucleus appears to correspond to part of the glomerular complex and lateral toral nucleus in other ray-finned fishes [5].

Labeled cells were also observed ipsilaterally in the midbrain tegmentum (t, Fig. 1I) and bilaterally in the superior raphe and locus coeruleus of the isthmus (Fig. 1J).

There are few data on afferents to the cells projecting to the telencephalon in bichirs. The anterior thalamic nucleus and its migrated satellite (nucleus a) receive direct bilateral retinal input $[5,15]$; thus the anterior thalamic nucleus forms part of a retino-thalamo-telencephalic circuit that appears to be homologous to a similar pathway reported in amphibians $[16,17]$. Although projections to other thalamic nuclei have not been experimentally determined in bichirs, the dorsal posterior thalamic nucleus receives a bilateral tectal input in gars [13] and the central posterior thalamic nucleus receives a bilateral toral input in Amia [2]. All of these data strongly suggest that the dorsal posterior and central posterior nuclei in bichirs are homologous to the sauropsid nucleus rotundus and nucleus medialis, respectively.

Similarly, cells of the posterior tuberculum project to the telencephalon in amphibians [20] as they do in bichirs, and these pathways appear to be comparable

Fig. 1. Chartings of retrogradely labeled neurons in diencephalic and mesencephalic nuclei (D-J) following HRP injections into the telencephalon $(\mathrm{A}-\mathrm{C})$. Fine and coarse stipple in $\mathrm{A}-\mathrm{C}$ indicate the extent of the core and annulus, respectively, of the HRP injection into the telencephalon. Black dots in $\mathrm{E}-\mathrm{J}$ indicate position of retrogradely labeled cells. Fine dots and dashes indicate anterogradely and retrogradely labeled fibers of the forebrain bundles. Abbreviations: a, anterior thalamic nucleus; $a^{\prime}$, migrated anterior thalamic nucleus; ac, anterior commissure; $b$, migrated cell group of ventral thalamus; $\mathrm{cp}$, central posterior thalamic nucleus; cpt, central pretectal nucleus; dp, dorsal posterior thalamic nucleus; ec, caudal entopeduncular nucleus; ed, dorsal entopeduncular nucleus; $g$, granular layer of cerebellum; h, habenular nuclei; hc, caudal hypothalamus; hco, habenular commissure; hd, dorsal hypothalamus; hv, ventral hypothalamus; i, intermediate thalamic nucleus; ip, interpeduncular nucleus; lc, locus coeruleus; m, nucleus medianus; ob, olfactory bulb; ot, optic tract; p, pallium; po, paraventricular organ and nucleus; pp, periventricular preoptic area; ppd, dorsal periventricular pretectal nucleus; ppv, ventral periventricular pretectal nucleus; P1-3, divisions of the pallium; sc, suprachiasmatic nucleus; sco, subcommissural organ; sp, superficial pretectal nucleus; sr, superior raphe; su, supracommissural nucleus; t, tegmentum; te, thalamic eminence; tel, telencephalon; tl, nucleus of torus lateralis; to, optic tectum; tp, nucleus of the posterior tuberculum; tpp, periventricular nucleus of the posterior tuberculum; ts, torus semicircularis; $v$, ventrolateral thalamic nucleus; $v d$, dorsal nucleus of area ventralis; vl, lateral nucleus of area ventralis; vm, ventromedial thalamic nucleus; vn, nucleus $n$ of area ventralis; vp, posterior nucleus of area ventralis; vs, supracommissural nucleus of area ventralis; vv, ventral nucleus of area ventralis; zl, zona limitans. 
to some nigral projections in amniotes. However, the nature of the information carried by nucleus medianus and the lateral toral nucleus, and their homologues in tetrapods, if any, remain to be established.

Histological preparations were carried out by Harry Sloan, and Mary Sue Northcutt assisted in many phases of the research. This work was supported by NIH Grants NS11006 and EY02485.

I Bass, A.H., Telencephalic Afferents and Efferents in the Channel Catfish, lctalurus punctatus, Ph.D. Dissertation, University of Michigan, 1979, $214 \mathrm{pp}$.

2 Braford, M.R., Jr. and McCormick, C.A., Some connections of the torus semicircularis in the bowfin, Amia calva: a horseradish peroxidase study, Neurosci. Abstr., 5 (1979) 139.

3 Braford, M.R., Jr, and Northcutt, R.G., Olfactory bulb projections in the bichir, Polypterus, J. comp. Neurol., 156 (1974) 165-178.

4 Braford, M.R., Jr. and Northcutt, R.G., Correlation of telencephalic afferents and SDH distribution in the bony fish Polypterus, Brain Res., 152 (1978) 157-160.

5 Braford, M.R., Jr. and Northcutt, R.G., Organization of the diencephalon and pretectum in rayfinned fishes. In R.G. Northcutt and R.E. Davis (Eds.), Fish Neurobiology, University of Michigan Press, in press.

6 Davis, R.E., Autoradiographic investigations of the central projections of the olfactory tracts in Macropodus opercularis (L.) (Osteichthyes: Belontidae), Neurosci. Abstr., 4 (1978) 218.

7 Echteler, S.M. and Saidel, W.M., Some connections of the teleost telencephalon, Neurosci. Abstr., 6 (1980) 629

8 Finger, T.E., The distribution of the olfactory tracts in the bullhead catfish, Ictalurus nebulosus, J. comp. Neurol., 161 (1975) 125-142.

9 Finger, T.E., Nonolfactory sensory pathway to the telencephalon in a teleost fish, Science, 210 (1980) $671-673$.

10 Ito, H. and Kishida, R., Telencephalic afferent neurons identified by the retrograde HRP method in the carp diencephalon, Brain Res., 149 (1978) 211-215.

11 Mesulam, M.-M., Tetramethyl benzidine for horseradish peroxidase neurohistochemistry: a noncarcinogenic blue reaction-product with superior sensitivity for visualizing neural afferents and efferents, J. Histochem. Cytochem., 26 (1978) 106-117.

12 Northcutt, R.G. and Braford, M.R., Jr., New observations on the organization and evolution of the telencephalon of actinopterygian fishes. In S.O. Ebbesson (Ed.), Comparative Neurology of the Telencephalon, Plenum Press, New York, pp. 41-98.

13 Northcutt, R.G. and Butler, A.B., Projections of the optic tectum in the longnose gar, Lepisosteus osseus, Brain Res., 190 (1980) 333-346.

14 Rakich, L., Belekhova, M.G. and Konevich, D., Visual projections in the telencephalon and diencephalon of the bony fish Serranus scriba: an electrophysiologic study, J. evolut. Biochem. Physiol, 15 (1979) 301-310.

15 Reperant, J., Rio, J.P. and Amouzou, M., Analyse radioautographique des projections rétiniennes chez le poisson osseux primitif Polypterus senegalus C., C.R. Acad. Sci. (Paris), 289 (1979) 947-950.

16 Ronan, M.C. and Northcutt, R.G., Afferent and efferent connections of the bullfrog medial pallium, Neurosci. Abstr., 5 (1979) 146.

17 Scalia, F. and Colman, D.R., Identification of telencephalic-afferent thalamic nuclei associated with the visual system of the frog, Neurosci. Abstr., 1 (1975) 46.

18 Scalia, F. and Ebbesson, S.O.E., The central projections of the olfactory bulb in a teleost fish (Gymnothorax funebris), Brain Behav. Evol., 4 (1971) 376-399.

19 Sharma, S.C. and Grover, B.G., Telencephalic afferents and the visual system in goldfish, Neurosci. Abstr., 4 (1978) 102.

20 Wilczynski, W., Connections of the Midbrain Auditory Center in the Bullfrog, Rana catesbeiana, Ph.D. Dissertation, University of Michigan, 1978, 196 pp. 